Research Paper:

\title{
Quality Management System and its Role in the Quality Maturity of Training Hospitals
}

\author{
Homa Seyedi $^{1}$ (D), Rafat Mohebbifar ${ }^{2}$ (D), Sima Rafiei ${ }^{* *}$ (D)
}

1. Student Research Center, School of Health, Qazvin University of Medical Sciences, Qazvin, Iran

2. Department of Health care Management, School of Health, Qazvin University of Medical Sciences, Qazvin, Iran.

3. Social Determinants of Health Research Center, School of Health, Qazvin University of Medical Sciences, Qazvin, Iran.

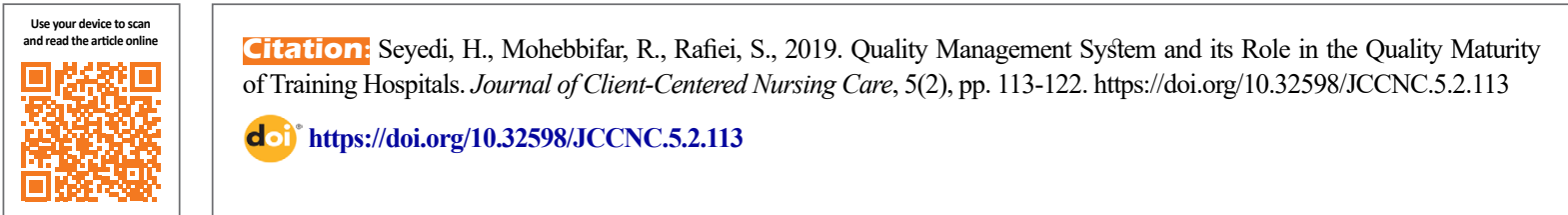

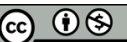

Article info:

Received: 05 Dec 2018

Accepted: 10 Mar 2019

Published: 01 May 2019

Keywords:

Quality management system, Quality

improvement, Hospital

\begin{abstract}
A B S T RA C T
Background: Recent trends have led many organizations to use strategic planning for designing and implementing Total Quality Management (TQM) as a fundamental necessity. This study investigated the role of TQM in the quality maturity of hospitals from the employees' point of view.

Methods: A cross-sectional study was conducted among the senior managers and officials of three Zanjan University of Medical Sciences (ZUMS) training hospital wards, including supervisors, matrons, and all hospital committee members. All the managers who were willing to participate and met the inclusion criteria were recruited. Two questionnaires, including TQM Assessment and Quality Maturity of Hospital Services were used. Statistical analyses were conducted by SPSS through multivariable regression modeling.

Results: The obtained results affirmed a significant effect of TQM on the quality improvement of hospital services; a unit of increase in the mentioned variable resulted in 0.63 unit of change in quality maturity $(\mathrm{P}<0.05)$. Furthermore, among the different aspects of the quality management system, the most significant impact on quality maturity belonged to having a system-wide approach toward management $(\beta=0.342)$.

Conclusion: To improve the quality of hospital services, it is necessary to promote managers and employees' commitment toward the necessity of effectively implementing quality improvement programs. Establishing a process management approach, developing a culture of continuous improvement, adopting a systematic approach to control managerial issues, and encouraging employees to participate in quality improvement goals are necessary in this regard.
\end{abstract}

\section{* Corresponding Author:}

Sima Rafiei, PhD.

Address: Social Determinants of Health Research Center, School of Health, Qazvin University of Medical Sciences, Qazvin, Iran

Tel: +98 (912) 3886817

E-mail: sima.rafie@gmail.com 


\section{Highlights}

- Adopting TQM is an effective approach in providing high-quality services by both individual and institutional providers.

- A new approach which has been taken into consideration for delivering quality services in hospitals is a called quality maturity.

- To achieve quality maturity, managers should be committed to TQM in a participative organizational environment using the potential collaboration of different parties, including managers, employees, patients, and suppliers.

\section{Plain Language Summary}

In Iran, there are limited research studies on quality maturity in healthcare centers; thus, hospital managers can contribute in such scientific area and provide evidence-based data to discover a set of factors which play an essential role in institutionalizing the quality maturity as a managerial necessity. According to the collected results, TQM affects the quality improvement of hospital services; any increase in TQM leads to changes in quality maturity. Furthermore, among the different aspects of quality management system, the greatest impact on quality maturity was related to having a system-wide approach toward management.

\section{Background}

\section{Quality as a competitive advantage}

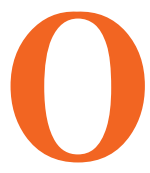

ver the past two decades, the importance of quality and its improvement as an important competitive advantage of organizations in a dynamic environment has attracted the attention of most managers. Hospitals, like other organizations, are faced with ever-increasing environmental pressures. This issue requires them to adapt to changing socio-economic and customer-based factors (Lieberthal 2008). These healthcare organizations have a critical role in providing biopsychological healthcare services for patients safely and with the most appropriate quality level (Hippisley-Cox et al. 2006). Recent trends have led many organizations to use strategic planning for designing and implementing TQM as a fundamental necessity. This explains why strategic management and quality improvement systems in the health sector have been welcomed in the last decades (Wright \& Shojania 2009).

\section{Quality management system}

Adopting TQM as an effective approach in providing high-quality services can act by both individual and institutional providers, leading to quality maturity in hospitals (Berces \& Hegyi 2001). Quality management includes 8 basic principles which senior managers can apply in healthcare organizations to improve perfor- mance. These principles include customer-oriented approach, strategic leadership, employee participation, process approach, system approach to management, continuous improvement, factual approach to decision making, and mutually beneficial supplier relationships (Mosadegh Rad 2004; Mosadegh Rad 2005). Considering these factors in healthcare settings helps providers with the competitive advantage of improving the effectiveness and overall performance toward achieving a superior global position (Antony et al. 2002; Counte \& Meurer, 2001).

\section{Quality maturity}

A new approach which has been taken into consideration for delivering quality services in hospitals is a term called "quality maturity"; it was first introduced and implemented in the health systems of some countries, including the USA and the United Kingdom. The main distinction existing between this quality evaluation approach and other measurement tools is its emphasis on strategic thinking and the implementation of organizational issues based on the strategic management process. Applying such approaches in hospitals assures the awareness toward environmental opportunities and threats as well as internal competitive advantages of an organization; thus, all activities on the allocation of resources are conducted per determined strategic goals (Groene et al. 2011). It also assists hospitals in progressing through the required organizational, strategic, and technical competences in a systematic manner. Therefore, the devel- 
opment of cooperative arrangements and processes would be proficient and effective (Mettler 2011).

A European project entitled "Methods of Assessing Response to Quality Improvement Strategies (MARQuIS)" developed a classification model for hospital quality improvement systems. The model measured quality improvement based on quality procedures, quality governance structures, and quality activities to minimize the gap between existing and desired levels of quality (Suñol et al. 2009). Furthermore, it evaluates 'maturity' by revealing the progressive phase of different quality improvement strategies.

To evaluate hospital status according to this index, a questionnaire entitled Maturity of the Quality in Hospital Services, including 6 critical aspects of management and leadership, results, human resources, information infrastructure and data management, knowledge, and skills improvement was used. That indicates the weaknesses and strengths of a hospital in each of the dimensions as a point on the continuum (Moradi et al. 2016). The domain scores were combined in a mean total mark for each hospital, representing the different points of a spectrum from beginner to advanced level. Such quality maturity model has become a key assessment tool for managing organizational change toward quality improvement processes.

Strategic thinking among managers and authorities at different levels of healthcare organizations is important. It is conducted by examining the status of quality management implementation in healthcare settings. However, it still unclear whether hospitals with a more established TQM perform better in terms of quality maturity indices. Therefore, this study aimed to investigate the success rate of TQM and its role in determining the quality maturity indicators of training hospitals affiliated to Zanjan University of Medical Sciences, in 2017.

\section{Materials and Methods}

This cross-sectional descriptive study was conducted in three ZUMS training hospitals in 2017. Senior managers and the heads of different hospital departments, including supervisors, matrons, and the key members of hospital committees participated in the research. The inclusion criteria were participation in hospital decision-making; in particular those on safety and quality improvement, and having at least one year of work experience at a hospital setting. Therefore, all individuals who were willing to participate and met the inclusion criteria $(\mathrm{n}=150)$ were recruited.
Data collection involved a "TQM Assessment Tool" and a standard questionnaire entitled "Quality Maturity of Hospital Services” (Lombart et al. 2009). The Persian version of the first questionnaire was developed by Mosadegh Rad (2005) and involved 34 questions. It measures respondents' perception regarding 8 dimensions, including customer-based services, leadership, employee participation, process approach, system approach to management, continuous improvement, factual approach to decision making, and mutually beneficial supplier relationships. A five-point Likert-type scale was used for this scale ( $1=$ strongly disagree to $5=$ strongly agree). The scores below 80 were regarded as the non-maturity of the hospital; while, the scores 80-126 indicated a moderate level of maturity.

Moreover, the scores above 126 were considered as a proper maturity condition. Face and content validity were confirmed in a study by a panel of experts, comprising hospital managers and authorities. Cronbach's alpha coefficient was used to assess the instrument reliability; values more than 0.7 were considered as an acceptable reliability (Mosadegh $\operatorname{Rad} 2005$ ).

To assess the level of quality maturity in hospitals, a self-administered checklist was used. It has been developed based on a standard questionnaire developed by Lombarts et al. (2008). It consisted of 19 items investigating 6 aspects of management and leadership, policy and planning, structure, results, resources, and data management. Each item was scored on a four-point scale ranging from 1 (Most mature) to 4 (Least mature). The mean score of these domains was pooled in a mean total score per hospital.

According to the results, the status of hospitals was categorized into 5 grades (beginner, developing, progressive, developed, and transcendental) based on the score limit between 19 and 76 . The reliability of the questionnaire was evaluated through a pilot study among 20 participants same as the research population. Calculated Cronbach's alpha (greater than 0.8) affirmed the internal consistency of the questionnaire. Then, the face validity of the questionnaire was checked by a panel of experts, including academic members of one of the Iran medical universities who had necessary experience in the field of the study. They reviewed all the questions and assessed them in terms of proportionality, transparency, and understandability. The questionnaires included a cover letter that briefly explained the study purpose and mechanisms to maintain data privacy. 
The collected data were analyzed SPSS. Appropriate statistical procedures were applied for description analysis, and the differences between groups were tested by the Chi-squared test, and Analysis of Variance (ANOVA). To evaluate the relationship between study variables, correlation coefficients were calculated. Furthermore, multivariate linear regression analysis was used to determine the predictors of quality maturity in study hospitals based on the participants' perspective. $\mathrm{P}<0.05$ were regarded as significant.

Table 1. Demographic characteristics of study participants

\section{Results}

The study participants' profile revealed that $56 \%$ were at the age group of $51-41$ years; $68 \%$ were female; $76.7 \%$ had a bachelor's degree, and $24.7 \%$ were nurses working in different hospital wards (Table 1).

Results regarding the success in implementing TQM in three hospitals under the study (including " $\mathrm{A}$ ", "B", and " $C$ ") and the quality maturity status of their services are presented in Table 2. Furthermore, the obtained data reflect possible differences in the mean values of these two variables among different hospitals.

\begin{tabular}{|c|c|c|}
\hline \multicolumn{2}{|r|}{ Variable } & \multirow{2}{*}{$\begin{array}{l}\text { No. (\%) } \\
48(32)\end{array}$} \\
\hline & Male & \\
\hline Gender & & \\
\hline & Female & $102(68)$ \\
\hline \multirow{5}{*}{ Age, $y$} & $<30$ & $13(8.7)$ \\
\hline & $31-40$ & $36(24)$ \\
\hline & 1150 & $84(56)$ \\
\hline & $41-50$ & $84(56)$ \\
\hline & $>50$ & $17(11.3)$ \\
\hline \multirow{3}{*}{ Education level } & Diploma & $2(1.3)$ \\
\hline & Bachelor's degree & $115(76.7)$ \\
\hline & Upper degrees & $33(22)$ \\
\hline \multirow{3}{*}{ Field of study } & Non-clinical & $30(20)$ \\
\hline & Clinical & $109(72.6)$ \\
\hline & Para-clinical & $11(7.4)$ \\
\hline \multirow{10}{*}{ Workplace } & Information technology & $1(0.6)$ \\
\hline & Medical records & $1(0.6)$ \\
\hline & Administrative affairs & $11(7.3)$ \\
\hline & Para-clinical wards & $1(0.6)$ \\
\hline & Internal and surgical wards & $96(64)$ \\
\hline & Quality improvement and patient safety department & $4(2.6)$ \\
\hline & Social work unit & $1(0.6)$ \\
\hline & Department of nutrition & $2(1.2)$ \\
\hline & Medical engineering department & $1(0.6)$ \\
\hline & Hospital committees & 32 (21.9) \\
\hline
\end{tabular}


Table 2. The mean success rate of TQM implementation and quality maturity in the studied hospitals

\begin{tabular}{|c|c|c|c|c|c|}
\hline \multirow{2}{*}{ Variable } & \multicolumn{4}{|c|}{ Mean $\pm S D$} & \multirow{2}{*}{$\mathbf{P}$} \\
\hline & A & B & C & Total & \\
\hline Focus on customers & $52 \pm 3.02$ & $52 \pm 3.6$ & $60 \pm 3.8$ & $59 \pm 3.7$ & 0.35 \\
\hline Leadership commitment & $37 \pm 3.94$ & $84 \pm 3.1$ & $61 \pm 3.5$ & $59 \pm 3.8$ & 0.05 \\
\hline Employee participation & $56 \pm 3.82$ & $59 \pm 3.2$ & $71 \pm 3.4$ & $65 \pm 3.3$ & 0.001 \\
\hline Process approach & $36 \pm 3.8$ & $47 \pm 3.6$ & $67 \pm 3.4$ & $58 \pm 5.3$ & 0.001 \\
\hline $\begin{array}{c}\text { Systemic approach to manage- } \\
\text { ment }\end{array}$ & $37 \pm 3.8$ & $51 \pm 3.4$ & $57 \pm 3.4$ & $58 \pm 5.3$ & 0.001 \\
\hline Continuous improvement & $36 \pm 3.8$ & $54 \pm .3 .4$ & $70 \pm 3.4$ & $64 \pm 3.4$ & 0.001 \\
\hline $\begin{array}{l}\text { Factual approach to decision- } \\
\text { making }\end{array}$ & $28 \pm 3.9$ & $52 \pm 3.3$ & $75 \pm 3.4$ & $64 \pm 3.4$ & 0.001 \\
\hline $\begin{array}{l}\text { Mutually beneficial supplier } \\
\text { relationships }\end{array}$ & $39 \pm 3.6$ & $64 \pm 3.3$ & $60 \pm 3.3$ & $61 \pm 3.3$ & 0.001 \\
\hline $\begin{array}{l}\text { Implementation of quality man- } \\
\text { agement system }\end{array}$ & $59.8 \pm 4.7$ & $66.9 \pm 2.5$ & $74.8 \pm 3.6$ & $61.8 \pm 6.5$ & 0.001 \\
\hline Management and leadership & $55.3 \pm 3.1$ & $53.2 \pm 5.1$ & $44.3 \pm 6$ & $71.3 \pm 5.7$ & 0.001 \\
\hline $\begin{array}{c}\text { Knowledge and skill for improve- } \\
\text { ment }\end{array}$ & $51.8 \pm 9.3$ & $52.3 \pm 7.2$ & $59 \pm 5.5$ & $54 \pm 6.7$ & 0.001 \\
\hline Resources & $54 \pm 9.3$ & $56 \pm 5.1$ & $61 \pm 5.3$ & $57 \pm 5.1$ & 0.18 \\
\hline Policy and planning & $31 \pm 9.3$ & $55 \pm 7.3$ & $64 \pm 5.7$ & $50 \pm 6.6$ & 0.33 \\
\hline Data management & $59.3 \pm 4.2$ & $52 \pm 6.6$ & $58 \pm 4.2$ & $56.3 \pm 6.3$ & 0.001 \\
\hline Structure & $59.2 \pm 6.2$ & $58.3 \pm 6.2$ & $60.2 \pm 6.3$ & $58 \pm 6.7$ & 0.001 \\
\hline Quality maturity & $60.1 \pm 9.7$ & $57.9 \pm 5.4$ & $61.5 \pm 7.2$ & $59.3 \pm 6.5$ & 0.001 \\
\hline
\end{tabular}

The Mean \pm SD score of TQM implementation in the studied hospitals was $61.8 \pm 6.5$, which represented a low level of program deployment. The mean scores related to most of the TQM dimensions were below 60, indicating an average of the low status of program implementation in hospitals. Furthermore, concerning all dimensions, hospital " $A$ " achieved the weakest status in implementing TQM principles.

Comparison between the three hospitals revealed that all TQM principles except for leadership commitment, and supplier relationships were applied to a greater extent in hospital " $C$ ". Regarding these two aspects, hospital "B" demonstrated better performance. Finally, ANOVA results affirmed the differences in the status of TQM implementation among the hospitals in all aspects except for focus on customers, and leadership commitment $(\mathrm{P}<0.05)$.
Results obtained from quality maturity status in studied hospitals revealed a moderate level of maturity (59.3 \pm 6.5$)$. Regarding this variable, all related dimensions except for management and leadership got the highest mean values in the hospital " $C$ ".

Furthermore, comparing the different dimensions of maturity suggested that from the managers' viewpoint, the highest and lowest mean values belonged to structure, and policy and management, respectively. Additionally, ANOVA results affirmed significant statistical differences among hospitals in all dimensions, except for resources, policy, and planning $(\mathrm{P}<0.05)$.

Table 3 indicates the importance of each TQM principle in the success of program implementation from the managers' perspective. The relevant results revealed that the greatest impact of dimensions belonged to a systematic approach to management, employee partici- 
Table 3. The effects of TQM principles on determining managers' viewpoint toward TQM implementation

\begin{tabular}{ccccc}
\hline TQM Principles & B & SE & t & P \\
\hline Employee participation & 0.189 & 0.0001 & 580.3 & 0.001 \\
Process approach & 0.17 & 0.0001 & 408 & 0.001 \\
\hline Systemic approach to management & 0.34 & 0.0002 & 798.5 & 0.001 \\
Continuous improvement & 0.186 & 0.0001 & 406.01 & 0.001 \\
\hline Factual approach to decision-making & 0.188 & 0.0001 & 470.01 & 0.001 \\
\hline Mutually beneficial supplier relationships & 0.188 & 0.0001 & 550.39 & 0.001 \\
\hline
\end{tabular}

Table 4. The association between TQM implementation and quality maturity in hospitals

\begin{tabular}{|c|c|c|c|}
\hline & Quality Maturity & $r$ & $\mathbf{P}$ \\
\hline \multirow{8}{*}{ TQM principles } & Focus on customers & 0.51 & 0.001 \\
\hline & Leadership commitment & 0.66 & 0.001 \\
\hline & Employee participation & 0.78 & 0.001 \\
\hline & Process approach & 0.62 & 0.001 \\
\hline & Systemic approach to management & 0.48 & 0.001 \\
\hline & Continuous improvement & 0.74 & 0.001 \\
\hline & Factual approach to decision-making & 0.55 & 0.001 \\
\hline & Mutually beneficial supplier relationships & 0.52 & 0.001 \\
\hline
\end{tabular}

pation, factual approach to decision making, and mutually beneficial supplier relationships.

As per Table 4, in correlation analysis between TQM implementation and quality maturity, employee participation $(\mathrm{r}=0.78)$, and continuous improvement $(\mathrm{r}=0.74)$ had a positive and most significant relationship with quality maturity in the studied hospitals. While, the lowest associations belonged to customer-based services ( $\mathrm{r}=0.51)$, and systematic approach to management $(\mathrm{r}=0.48)$. To examine the importance of demographic diversity in the perspective of managers toward quality maturity, linear regression modeling was performed. Table 5 illustrates the associated results.

Table 5. Predictive role of study participants' demographic variables in their attitude toward quality maturity

\begin{tabular}{|c|c|c|c|c|c|}
\hline \multirow[t]{2}{*}{ Demographic Variables } & \multicolumn{2}{|c|}{ Unstandardized Coefficients } & \multirow{2}{*}{ Standardized Coefficient } & \multirow{2}{*}{$\mathbf{t}$} & \multirow{2}{*}{$\mathbf{P}$} \\
\hline & B & SE & & & \\
\hline Gender & 2.2 & 1.3 & 0.11 & 1.5 & 0.06 \\
\hline Age, $y$ & -0.52 & 1.1 & -0.033 & -0.32 & 0.5 \\
\hline Education level & 6.1 & 1.1 & 0.51 & 3.52 & 0.001 \\
\hline Field of study & 1.68 & 0.65 & 0.23 & 1.48 & 0.001 \\
\hline Work place & 0.12 & 0.9 & 0.01 & 0.12 & 0.02 \\
\hline
\end{tabular}


Table 6. Predictive role of TQM implementation in managers' attitude toward quality maturity

\begin{tabular}{|c|c|c|c|c|c|c|}
\hline \multirow{2}{*}{ Variables } & \multirow{2}{*}{ B } & \multirow{2}{*}{ SE } & \multirow{2}{*}{$\mathbf{t}$} & \multirow{2}{*}{$\mathbf{P}$} & \multicolumn{2}{|c|}{ Confidence Interval } \\
\hline & & & & & Low Limit & High Limit \\
\hline TQM Implementation & 0.636 & 0.07 & 9.01 & 0.001 & 1.38 & 2.35 \\
\hline Focus on customers & -0.07 & 0.006 & -0.922 & 0.358 & 0.016 & 0.006 \\
\hline Leadership commitment & 0.07 & 0.007 & 0.672 & 0.502 & 0.009 & 0.019 \\
\hline Employee participation & 0.184 & 0.005 & 25.67 & 0.001 & 0.112 & 0.131 \\
\hline Process approach & 0.168 & 0.006 & 19.72 & 0.001 & 0.111 & 0.136 \\
\hline Systemic approach to management & 0.344 & 0.006 & 38.92 & 0.001 & 0.239 & 0.164 \\
\hline Continuous improvement & 0.188 & 0.006 & 19.59 & 0.001 & 0.113 & 0.138 \\
\hline Factual approach to decision-making & 0.185 & 0.005 & 22.53 & 0.001 & 0.112 & 0.134 \\
\hline Mutually beneficial supplier relationships & 0.190 & 0.005 & 26.84 & 0.001 & 0.117 & 0.136 \\
\hline
\end{tabular}

In exploring the relationship between demographic variables and managers' viewpoint toward quality maturity, study results confirmed that the field of study and educational level had significant effects on the dependent variable $(\mathrm{P}<0.05)$. Leveling up to a higher educational level led to a 0.51 unit of development in quality maturity. In the multiple linear regression model based on the backward method, these two variables were controlled as confounding variables in the relationship between TQM implementation and quality maturity. The obtained results confirmed that the associated factor with the dependent variable was determined as TQM implementation $(\mathrm{P}<0.05)$, which remained significant after adjusting confounding variables $(\beta=0.63, \mathrm{P}<0.05)$. In other words, one unit change in the standard deviation of the independent variable would respectively lead to 0.63 unit change in the standard deviation of quality maturity.

Furthermore, the regression model predicted $67 \%$ of changes in the dependent variable (ADJ.R ${ }^{2}=0.67$ ). As per Table 6, managers with a more positive attitude toward TQM implementation assessed the quality maturity of the hospital more favorably. Studying the effects of different TQM aspects on quality maturity also suggested that the most significant role among 8 dimensions belonged to systemic approach to management $(\beta=0.344 ; \mathrm{P}<0.05)$.

\section{Discussion}

Healthcare managers and policymakers should consider the importance of delivering high-quality services with sufficient effectiveness and efficiency. To this purpose, implementing a quality management system can be a beneficial strategy, which helps healthcare providers take more effective steps toward achieving quality goals (Mosadegh Rad 2005).

Study results suggested that the overall viewpoint of managers toward the implementation of TQM in hospitals was not appropriate with the greatest impact of systematic approach to management, employee participation, factual approach to decision making, and mutually beneficial supplier relationships. In a similar study, Mosadegh Rad (2005) reported that TQM improvement is highly dependent on managerial commitment, employee participation, and measurement of their performance through appropriate criteria. Furthermore, Sadikoglu and Olcay (2014) believed that considering employees as valuable organizational resources and evolving them in decision-making affairs increase their trustworthiness and persuade them in conducting their work-related performance in an effective manner.

Leggat (2007) noted that organizations with lowquality services tend to consider quality improvement activities as a job monopolized by a person; the use of employee participation in decision-making and accomplishing job affairs are overlooked with the goal of continuous improvement. Mosadegh Rad (2005) concluded that the successful implementation of TQM mainly depends on the leadership efforts and cooperative activities of all personnel in an organization with a learning culture which develops process-management practices and continuous employee empowerment. The author also believed that successful TQM requires skillful staff committed to quality improvement activities. 
Top management support, workforce participation, supplier involvement, and quality information system were other influential factors mentioned by Dayton (2001) as being significant to the successful TQM implementation. Asmoni et al. (2015) revealed the most significant factors affecting the successful establishment of a quality management system. They found that focus on the customers was at the most satisfactory status, compared to other aspects. Study participants also believed that paying attention to the satisfaction of patients' needs by providing high-quality services and continuous monitoring of their needs got the highest priority in the successful implementation of a quality management system.

Similarly, Kaziliūnas (2010) affirmed the importance of such factors and emphasized on their necessity in the successful deployment of quality management system in organizations. Focusing on customers has also been considered as the main factor in the success of quality management efforts (Winser \& Corney 2001; Li et al. 2001; Nakata 2002). Literature notified that ignoring patients and their needs could lead to TQM failure in healthcare organizations (Behshid 2003; Mosadegh Rad 2005). Thus, health administrations should develop a systematic approach for receiving patients' suggestions and evaluate their satisfaction with rendered services.

Comparatively, a study was conducted to determine factors affecting the implementation of a quality management system in healthcare centers affiliated with Isfahan University of Medical Sciences. It was revealed that some aspects, including the commitment of managers, employee participation, effective communication with suppliers, and data management were at a low level according to employees' viewpoint. This finding reflected the importance of strengthening the abovementioned dimensions in study centers with the purpose of improving the status of quality management system (Sadikoglu \& Zehir 2010).

In the current study, the quality maturity of hospital services was reported at a moderate level. In terms of different aspects of quality maturity, the staff reported the management and leadership at the most desirable condition and policy and planning at the most unfavorable situation. Similarly, Joyce et al. (1997) assessed the latter feature to be undesirable and suggested that continuing education as a critical factor in improving the quality of urban emergency services in Oregon could be a helpful strategy. They also added that sufficient resources and an appropriate information system would be useful in the quality maturity of services.
Furthermore, our findings revealed that some factors, including resources, knowledge, and skill for improvement, and data management were at a relatively unfavorable level. According to Amiri \& Sakaki (2005), organizations were considered as mature entities when there was a high level of managerial commitment and responsibility toward quality improvement. They believed that maturity would only be achieved through developing a proper culture of change among all managers in different organizational levels and the design of effective educational interventions in this regard. They also noted that employees' participation would be flourished if there is a sufficient managerial commitment toward quality improvement and systematic approach in leading the organization.

Ramadan \& Arafeh (2016) introduced a model to identify the status quo of quality implementation in healthcare institutions. The model consisted of 6 quality drivers, including management, human resources, processes, culture, quality focus, and accreditation. In another study entitled differentiating between hospitals according to the maturity of quality improvement systems, a model consisting of 7 domains was developed to evaluate European hospitals based on a quality improvement maturity index (Lombarts et al. 2009).

Moreover, our study found that various efforts in the field of TQM have significantly affected the different dimensions of quality maturity, mostly policy, and planning, as well as the improvement of knowledge and skills among employees. Thus, adopting appropriate policies for the establishment of an employee performance monitoring system besides designing a systematic approach for data management should be considered as effective strategies to improve the quality of hospital services. As a result, errors or deviations in work processes can be easily detected and modified through process improvement. Furthermore, as literature suggests, training is positively related to employee performance and the improvement of their knowledge and skills. Allocating adequate resources for employee training and culture building on quality issues not only advance the organization on the path to quality improvement but also bring significant competitive advantages to the whole system (Yusof \& Aspinwall 2000; Calisir et al. 2001).

In addition, considering employees as a valuable intellectual capital was regarded as another key factor. This may lead to the successful implementation of a quality management system through the effective use of their creative ideas in promoting work processes and systematic improvement of the running system. If the staff 
viewpoints are considered in determining objectives and strategies, the employees will determinedly support and enforce related strategies. The main reason is that employees feel like they are important role players in the organization and their efforts are crucial to the achievement of objectives (Mosadegh Rad 2005; McAdam \& Kelly 2002; Buch \& Rivers 2002). Therefore, employee participation in decision-making processes, their continuous empowerment, and the systematic supervision of them will be used in an essentially proper way.

Effective interaction with suppliers was another important priority which prominently influenced the quality maturity of the services. Such relationship promotes the quality of rendered services, provides an effective monitoring system, and improves suppliers' loyalty to the organization's expectations (Mosadegh $\operatorname{Rad} 2003$ \& 2004). Literature has also revealed that supplier management is a leading factor for social responsibility. All role players in the supply chain should realize the influence of their services on society's health condition. They should also manage their activities in line with the principles of a quality management system. Through this evaluation system, all of their activities would be evaluated concerning quality and performance improvement measures.

To achieve quality maturity, managers should be committed to TQM in a participative organizational environment using the potential collaboration of different parties, including managers, employees, patients, and suppliers. Implementing quality management systems improves various quality measures in healthcare organizations. Thus, all of its aspects should be effectively implemented in a hospital to bring about significant improvements regarding quality measures. Furthermore, to successfully implement TQM, several factors are essential. Managerial commitment, well-trained human resources, the culture of responsibility toward quality, customer-driven approaches, employee participation, sufficient resources, and effective communication were among some of the main intensives.

In conclusion, to proceed in a quality pathway, it is required to notify managers and employees about the vital role of deploying quality programs in healthcare systems. In Iran, there are limited research studies on quality maturity in healthcare centers; thus, hospital managers can contribute in such scientific areas and provide evidencebased data to discover the set of factors that play an important role in institutionalizing the quality maturity as a managerial necessity. Such information can effectively lead them toward providing sufficient opportunities, and create a proper condition in which high-quality endeavors could be achieved more probably.

There were two main limitations to the current study. First, data concerning TQM performance measures were gathered from the respondents mostly contained managers and those responsible for quality improvement activities which might have a desire to show their hospitals look good. In addition, the study hospitals are affiliated by Zanjan University of Medical Sciences as a public medical sciences university in Zanjan Province, Iran. This might restrict the generalizability of study results. Thus, it is recommended that similar studies be repeated in different contexts.

\section{Ethical Considerations}

\section{Compliance with ethical guidelines}

The study proposal was approved by the Ethics Committee of Qazvin University of Medical Sciences (code: IR.QUMS.REC.1396.18). Written consents were obtained from eligible personnel who agreed to participate in the study. The consent form contained information on the purpose of study, data confidentiality, voluntarily participation, and the opportunity to leave the study at any stage.

\section{Funding}

This research did not receive any specific grant from funding agencies in the public, commercial, or not-forprofit sectors.

\section{Authors' contributions}

Study design: Rafat Mohebbifar and Sima Rafi; Collectingstudy data: Homa Seyedi; Analyzing data and drafting the manuscript: Sima Rafi; Checking and confirming the written article: All authors.

\section{Conflict of interest}

Authors declared no conflict of interest.

\section{References}

Amiri, M. R., \& Sakaki, M. R., 2005. [Guideline for assessing or ganization performance using EFQM excellence model (Persian)]. Tehran: Institute for Productivity \& Human Resource Development Publishing.

Antony J., et al., 2002. Critical success factors of tqm implementation in hong kong industries. International Journal of Quality $\mathcal{E}$ Reliability Management, 19(5), pp. 551-66. [DOI:10.1108/02656710210427520] 
Asmonia, M. N. A., et al., 2015. Critical success factors of project quality management system for Malaysian construction industry. Journal Teknologi (Sciences \& Engineering), 74(2), pp. 123-31. [DOI:10.11113/jt.v74.4532]

Behshid, M., 2003. The survey of reasons of TQM failure. Paper presented at: The $2^{\text {nd }}$ Congress in Total Quality Management in Health Care, Tehran.

Buch, K., Rivers, D., 2002. Sustaining a quality initiative. Strategic Direction. 18(4), pp. 15-17. [DOI:10.1108/02580540210793437]

Calisir, F., Bayraktar, C., \& Beskese, B., 2001. Implementing the ISO 9000 standards in Turkey: A study of large companies satisfaction with ISO 9000. Total Quality Management, 12(4), pp. 429-38. [DOI:10.1080/09544120124029]

Counte, M. A. \& Meurer, S., 2001. Issues in the assessment of continuous quality improvement implementation in health care organizations. International Journal for Quality in Health Care, 13(3), pp.197-207. [DOI:10.1093/intqhc/13.3.197] [PMID]

Dayton, N. A., 2001. Total quality managementcritical successfactors, a comparison: The UK versus the USA. Total Quality Management, 12(3), pp. 293-8. [DOI:10.1080/09544120120034447]

Groene, O., et al., 2011. Is the maturity of hospitals' quality improvement systems associated with measures of quality and patient safety? BMC Health Services Research, 11, p. 344. [DOI:10.1186/1472-6963-11-344] [PMID] [PMCID]

Hippisley-Cox, J., et al., 2006. Sex inequalities in access to care for patients with diabetes in primary care: Questionnaire survey. British Journal of General Practice, 56(526), pp. 342-8. [PMID] [PMCID]

Joyce, S. M., Dutkowski, K. L. \& Hynes, T., 1997. Efficacy of an EMS quality improvement program in improving documentation and performance. Prehospital Emergency Care, 1(3), pp.140-4. [DOI:10.1080/10903129708958807] [PMID]

Kaziliūnas, A., 2010. The implementation of quality management systems in service organizations. Public Policy and Administration, 34, pp. 71-82.

Leggat, S. G., 2007. Effective healthcare teams require effective team members: Defining teamwork competencies. BMC Health Services Research, 7, p. 17. [DOI:10.1186/1472-6963-7-17] [PMID] [PMCID]

Li, E. Y., Zhao, X. \& Lee, T.S., 2001. Quality management initiatives in Hong Kong's banking industry: A longitudinal study. Total Quality Management,12(4), pp. 451-67. [DOI:10.1080/09544120125408]

Lieberthal, R. D., 2008. Hospital quality: A PRIDIT approach. Health Services Research,43(3), pp. 988-1005. [DOI:10.1111/j.1475-6773.2007.00821.x] [PMID] [PMCID]

Lombarts, M. J. M. H., et al., 2009. Differentiating between hospitals according to the "maturity" of quality improvement systems: A new classification scheme in a sample of European hospitals. BMJ Quality \& Safety, 18(Suppl. 1), pp. i38-i43. [DOI:10.1136/qshc.2008.029389] [PMID] [PMCID]

McAdam, R. \& Kelly, M., 2002. A business excellence approach to generic benchmarking in SMEs. Benchmarking: An International Journal, 9(1), pp. 7-27. [DOI:10.1108/14635770210418551]

Mettler, T., 2011. Transformation of the hospital supply chain: How to measure the maturity of supplier relationship management systems in hospitals? International Journal of Healthcare Information Systems and Informatics, 6(2), pp.1-13. [DOI:10.4018/jhisi.2011040101]

Moradi, T., et al., 2016. Quality management systems implementation compared with organizational maturity in hospital. Global Journal of Health Science, 8(3), pp. 174-82. [DOI:10.5539/gihs.v8n3p174] [PMID] [PMCID]

Mosadegh Rad, A. M., 2003. [The principles of health care administration (Persian)]. Tehran: Dibagran.

Mosadegh Rad, A.M., 2004. [A step to total quality management (Persian)]. Management and Development Process Quarterly, 55, pp. 32-41.

Mosadegh Rad, A. M., 2005. A survey of total quality management in Iran. Leadership in Health Services, 18(3), pp.12-34. [DOI:10.1108/13660750510611189]

Nakata, C., 2002. Activating the marketing concept in a global context: An MNC country managers' perspective. International Marketing Review, 19(1), pp. 39-64. [DOI:10.1108/02651330210419724]

Ramadan, N. \& Arafeh, M., 2016. Healthcare quality maturity assessment model based on quality drivers. International Journal of Health Care Quality Assurance, 29(3), pp. 337-50. [DOI:10.1108/IJHCQA-08-2015-0100] [PMID]

Sadikoglu, E. \& Zehir, C., 2010. Investigating the effects of innovation and employee performance on the relationship between total quality management practices and firm performance: An empirical study of Turkish firms. International Journal of Production Economics, 127(1), pp. 13-26. [DOI:10.1016/j. ijpe.2010.02.013]

Sadi Sadikoglu, E. \& Olcay, H., 2014. The effects of total quality management practices on performance and the reasons of and the barriers to TQM practices in Turkey. Advances in Decision Sciences, 2014(537605), pp. 1-17. [DOI:10.1155/2014/537605]

Suñol, R., Garel, P., \& Jacquerye, A., 2009. Cross-border care and healthcare quality improvement in Europe: The MARQuIS research project. BMJ Quality \& Safety, 18(Suppl. 1), pp. i3-i7. [DOI:10.1136/qshc.2008.029678] [PMID] [PMCID]

Wisner, J. D. \& Corney, W. J., 2001. Comparing practices for capturing bank customer feedback-Internet versus traditional banking. Benchmarking: An International Journal, 8(3), pp. 24050. [DOI:10.1108/14635770110396647]

Wright, J., \& Shojania, K. G., 2009. Measuring the quality of hospital care. $B M J, 338$, p. 569. [DOI:10.1136/ bmj.b569] [PMID]

Yusof, S. R. M. \& Aspinwall, E. M., 2000. Critical success factors in small and medium enterprises: Survey results. Total Quality Management, 11(4-6), pp. 448-62. [DOI:10.1080/09544120050007760] 